University of Wollongong

Research Online

Faculty of Engineering and Information

Faculty of Engineering and Information

Sciences - Papers: Part A

Sciences

$1-1-2013$

Net section tension capacity of cold-reduced sheet steel channel braces bolted at the web

Lip H. Teh

University of Wollongong, Iteh@uow.edu.au

Benoit P. Gilbert

Griffith University, b.gilbert@griffith.edu.au

Follow this and additional works at: https://ro.uow.edu.au/eispapers

Part of the Engineering Commons, and the Science and Technology Studies Commons

Research Online is the open access institutional repository for the University of Wollongong. For further information contact the UOW Library: research-pubs@uow.edu.au 


\title{
Net section tension capacity of cold-reduced sheet steel channel braces bolted at the web
}

\begin{abstract}
This paper examines the accuracy of equations specified by the North American and Australasian steel structures codes for determining the net section tension capacity of a channel brace. It points out that there are three distinct factors affecting the net section efficiency of a cold-formed steel channel brace bolted at the web. These factors are the in-plane shear lag associated with stress concentration around a bolt hole that is also present in flat sheets, the out-of-plane shear lag that is also present in an I-section bolted at the flanges only, and the bending moment arising from the connection eccentricity with respect to the neutral axis. Each of the relevant factors is explicitly incorporated in the equation proposed in this paper for determining the net section tension capacity of a cold-formed steel channel brace bolted at the web. The proposed equation is demonstrated through laboratory tests on low ductility channel braces having practical aspect ratios that were bolted onto flexible plates to be more reliable than the code equations and those existing in the literature.
\end{abstract}

\section{Keywords}

sheet, steel, channel, braces, net, section, tension, bolted, capacity, web, cold, reduced

Disciplines

Engineering | Science and Technology Studies

\section{Publication Details}

Teh, L. H. \& Gilbert, B. P. (2013). Net section tension capacity of cold-reduced sheet steel channel braces bolted at the web. Journal of Structural Engineering, 139 (5), 740-747. 


\title{
Net Section Tension Capacity of Cold-Reduced Sheet Steel Channel Braces Bolted at the Web
}

\author{
Lip H. Teh, A.M.ASCE ${ }^{1}$; and Benoit P. Gilbert ${ }^{2}$
}

\begin{abstract}
This paper examines the accuracy of equations specified by the North American and Australasian steel structures codes for determining the net section tension capacity of a channel brace. It points out that there are three distinct factors affecting the net section efficiency of a cold-formed steel channel brace bolted at the web. These factors include (1) the in-plane shear lag associated with stress concentration around a bolt hole that is also present in flat sheets, (2) the out-of-plane shear lag that is also present in an I-section bolted at the flanges only, and (3) the bending moment arising from the connection eccentricity with respect to the neutral axis. Each of the relevant factors is explicitly incorporated into the equation proposed in this paper for determining the net section tension capacity of a cold-formed steel channel brace bolted at the web. The proposed equation is demonstrated through laboratory tests on low-ductility channel braces having practical aspect ratios that were bolted onto flexible plates, to be more reliable than the code equations and those existing in the literature. DOI: 10.1061/(ASCE)ST.1943541X.0000650. (ㅇ 2013 American Society of Civil Engineers.
\end{abstract}

CE Database subject headings: Bolted connections; Cold-formed steel; Shear lag; Tensile strength; Thin wall sections; Bracing; Webs (structural).

Author keywords: Bolted connections; Cold-formed steel; Shear lag; Tensile strength; Thin wall sections.

\section{Introduction}

The net section tension capacity of a bolted connection in coldformed steel channel brace is specified in Supplement No. 2 to the North American Specification for the Design of Cold-formed Steel Structural Members 2007 [American Iron and Steel Institute (AISI) 2010] and in the Australasian code AS/NZS 4600:2005 [Standards Australia/Standards New Zealand (SA/SNZ) 2005]. For a channel brace that is bolted at the web only, the two code equations have different forms.

The design equation specified in the current North American code (AISI 2010) was recommended by LaBoube and Yu (1996) based on their laboratory test results, and is in a similar basic form to the equation proposed by Chesson (1959) to account for shear lag in a steel member where not all of its cross-sectional elements are bolted to the joining member. The original equation (Chesson 1959) is still being used without modification in the current AISC specification for structural steel buildings [American Institute of Steel Construction (AISC) 2010]. The shear lag factors (termed the "net section efficiency factor" in the present work for reasons explained later) in both the original equation and the modified version (AISI 2010) are functions of the connection eccentricity and the connection length only.

Maiola et al. (2002) and Pan (2004) found the design equation specified in the North American cold-formed steel code to be

\footnotetext{
${ }^{1}$ Senior Lecturer, School of Civil, Mining and Environmental Engineering, Univ. of Wollongong, Wollongong, NSW 2500, Australia (corresponding author). E-mail: 1teh@uow.edu.au

${ }^{2}$ Lecturer, School of Engineering, Griffith Univ., Gold Coast, QLD 4222, Australia.

Note. This manuscript was submitted on August 4, 2011; approved on May 16, 2012; published online on May 18, 2012. Discussion period open until October 1, 2013; separate discussions must be submitted for individual papers. This paper is part of the Journal of Structural Engineering, Vol. 139, No. 5, May 1, 2013. CASCE, ISSN 0733-9445/2013/5-740-747/ $\$ 25.00$.
}

unconservative when verified against their laboratory test results. The latter proposed an equation that is a function of the connection eccentricity, the connection length, the web depth, and the flange width (Pan 2004).

The design equation specified in the Australasian code (SA/SNZ 2005), on the other hand, makes use of neither the geometric properties nor the connection length of the section. For channel sections, the net section efficiency factor is a constant depending on whether the connection is single or back-to-back. The equation in the Australasian cold-formed steel code has been adopted from the Australian steel structures code AS 4100 [Standards Australia (SA) 1998]. Pan (2004) found the code equation to be unconservative.

This study aims to formulate a simple equation that is reliable in predicting the net section tension capacity of practical bolted connections in cold-formed steel channel braces having low material ductility. For this purpose, laboratory tests on channel braces bolted at the web only were conducted. The sections were made of G450 sheet steels by brake pressing. Care was taken to ensure that the connecting elements of the test specimens had bending flexibility that could be realistically encountered in actual constructions for channel braces.

In formulating the design equation, account was taken of the fact that the net section efficiency of a channel brace bolted at the web is affected by three factors not explicitly recognized to be distinct from each other in the literature. The first is the in-plane shear lag associated with stress concentration around the bolt holes, which also affects connections in flat sheets (Teh and Gilbert 2012). The second is the out-of-plane shear lag that occurs when the channel is bolted at the web only, a phenomenon that is also present in a bisymmetric I-section bolted at the flanges only (Munse and Chesson 1963). The third is the bending moment arising from the connection eccentricity with respect to the neutral axis (Epstein and Aiuto 2002).

To to avoid confusion, the term "shear lag factor" used in the AISC (2010) and AISI (2010) specifications is therefore replaced in this work by the term "net section efficiency factor." 


\section{Equations for Net Section Tension Capacity of a Channel Brace}

\section{Code Equations}

Clause 3.2.2(2) of AS/NZS 4600:2005 (SA/SNZ 2005) specifies the net section tension capacity of a bolted connection in a steel member to be

$$
P_{p}=0.85 k_{t} A_{n} F_{u}
$$

in which $A_{n}=$ net area of section; and $F_{u}=$ material tensile strength of member. The variable $k_{t}=$ net section efficiency factor, which is equal to unity for a connection that ensures uniform stress distribution over the net section.

The clause is adopted from Clause 7.2 of AS 4100-1998 (SA 1998). As explained in the commentary to the clause (SA 1999), the explicit coefficient of 0.85 embedded into Eq. (1) of the present paper "is intended to account for sudden failure by local brittle behavior at the net section." The apparent reason for the sudden brittle failure that is not accounted for using a lower capacity factor (or resistance factor) is that a uniform capacity factor of 0.90 is applied to the net-section fracture mode and the member-yielding (over the gross section) mode. Therefore, the effective capacity factor actually applied to the net-section-fracture mode is 0.765 .

Because Table 3.2 of the Australasian code (SA/SNZ 2005) specifies the value of $k_{t}$ for a channel brace bolted at the web to be 0.85 [not to be confused with the explicit coefficient of the same value in Eq. (1)], for the purpose of the present work Eq. (1) is replaced by

$$
P_{p}=k_{t} A_{n} F_{u}=0.85 A_{n} F_{u}
$$

which means that, according to the Australasian code, the net section efficiency factor for a channel brace bolted at the web is invariably 0.85 .

Section E5.2 of Supplement No. 2 to the North American Specification for the Design of Cold-formed Steel Structural Members 2007 (AISI 2010) specifies the net section tension capacity of a channel brace bolted at the web to be

$$
P_{p}=A_{n} F_{u} \max \left[0.5, \min \left(0.9,1-0.36 \frac{\bar{x}}{L}\right)\right]
$$

in which $\bar{x}=$ distance between the outer face of the web and the neutral axis of the section (i.e., the connection eccentricity); and $L=$ connection length. These variables are defined in Fig. 1. The net
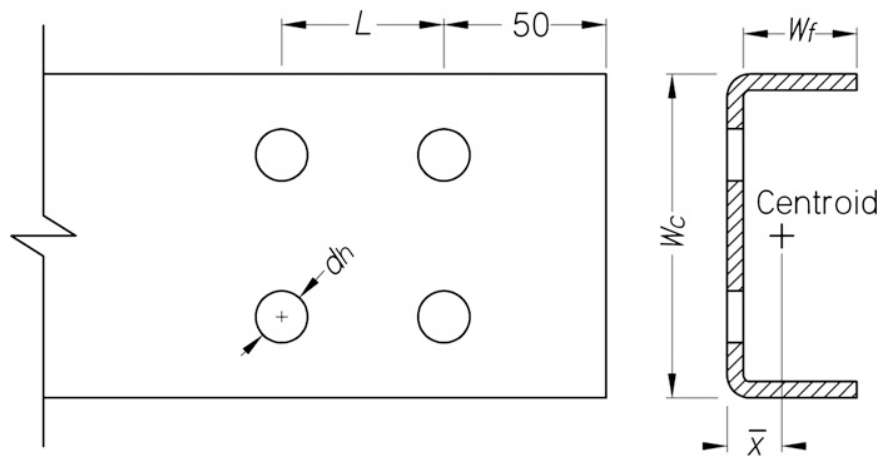

Fig. 1. Geometric dimensions of a channel member bolted at the web section efficiency factors given by Eq. (3) for channel braces bolted at the web vary between 0.5 and 0.9 .

Maiola et al. (2002) and Pan (2004) found Eq. (3) to be unconservative. The equation was proposed by LaBoube and $\mathrm{Yu}$ (1996) based on their laboratory test results and the original equation proposed by Chesson (1959) to account for shear lag in a steel member in which not all of its cross-sectional elements are bolted to the joining member. The original equation is still used in the current AISC specification for structural steel buildings (AISC 2010) with a lower bound shear lag factor equal to the ratio of the connected width to the total width

$$
P_{p}=A_{n} F_{u} \max \left(1-\frac{\bar{x}}{L}, \frac{W_{c}}{W_{c}+2 W_{f}}\right)
$$

in which $W_{c}=$ web depth; and $W_{f}=$ flange width, as defined in Fig. 1.

\section{Equations Presented in the Literature}

Holcomb et al. (1995) proposed the following equation for channel braces bolted at the web, based on nonlinear regression analysis of laboratory test results for angle sections

$$
P_{p}=A_{n} F_{u}\left(2.39 \frac{t}{W_{c}+\bar{x}}+0.308\right)\left(\frac{\bar{x}}{L}\right)^{-0.301}
$$

in which $t=$ section thickness. It can be seen that Eq. (5) involves a power term.

Epstein and Aiuto (2002) presented a procedure that accounts for the interaction between the axial force and the bending moment resulting from the eccentricity of the axial force from the neutral axis of a tee section. However, Epstein and Aiuto (2002) stated that the procedure is "too involved."

Based on laboratory test results, Pan (2004) concluded that the net section tension capacity of a channel brace bolted at the web was mainly influenced by the ratio of the connection eccentricity to the connection length and by the ratio of the flange width to the web depth. Pan (2004) proposed the following empirical equation using regression analysis

$$
P_{p}=A_{n} F_{u}\left(1.15-0.86 \frac{\bar{x}}{L}-0.28 W_{f} / W_{c}\right)
$$

The definition of the connection eccentricity $\bar{x}$ given in Pan (2004) is the same as that shown in Fig. 1. However, Chi-Ling Pan (personal communication, August 1,2011) has since advised the authors that he actually adopted the definition given in the 1993 AISC Specification (AISC 1993), which had been revised in the subsequent specification (AISC 1999), and the revised definition is shown in Fig. 1. Kirkham and Miller (2000) stated that the 1993 definition was revised because the available test data did not support the usage.

A robust empirical equation should provide plausible answers when applied to known conditions, to prevent potential anomalies, as illustrated by Teh and Gilbert (2012). If Eq. (6) is applied to a channel section with $W_{f}$ approaching zero, i.e., it is becoming a flat sheet, and therefore $\bar{x}$ also approaches zero, then the predicted failure load given by Eq. (6) will approach

$$
P_{p}=1.15 A_{n} F_{u}
$$

which implies a net section efficiency factor that is significantly greater than unity. 


\section{Proposed Equation}

Teh and Gilbert (2012) have shown that the net section tension capacity of bolted connections in flat steel sheet can be represented by

$$
P_{p}=A_{n} F_{u}\left(0.9+0.1 \frac{\sum_{1}^{n_{b}} d_{i}}{W}\right)
$$

in which $d_{i}=$ diameter of bolt; $n_{b}=$ number of bolts in the considered cross-section; and $W=$ width of the sheet perpendicular to the tension force.

The minimum bolt spacing specified in the Australasian standard (SA/SNZ 2005) and in Appendix A of the North American specification (AISI 2007) is three times the bolt diameter. If this requirement is met, then the largest in-plane shear lag factor given by Eq. (8) in practice is 0.933 , and the absolute minimum is 0.9 , as the ratio of the (sum of the) bolt diameter to the sheet width approaches zero.

Based on Eq. (8) and the conclusion of Pan (2004) that the net section tension capacity of a channel brace bolted at the web was mainly influenced by the ratio of the connection eccentricity to the connection length and by the ratio of the flange width to the web depth, which should be treated as independent variables, the following equation is proposed to predict the net section tension capacity of a channel brace bolted at the web

$$
P_{p}=A_{n} F_{u}\left(\frac{1}{1.1+\frac{W_{f}}{W_{c}+2 W_{f}}+\frac{\bar{x}}{L}}\right)
$$

As the flange width $W_{f}$ and the connection eccentricity $\bar{x}$ approach zero, i.e., the section approaches a flat sheet, the efficiency factor embedded in Eq. (9) approaches 0.91 , which is a reasonable, if conservative, approximation for bolted connections in cold-reduced steel sheet, as evident from Eq. (8). This result is also consistent with the upper-bound value of 0.9 specified in Eq. (3).

The constant of 1.1 in the denominator of Eq. (9) therefore accounts for the in-plane shear lag effect present in the steel sheet (Teh and Gilbert 2012), and the term $W_{f} /\left(W_{c}+2 W_{f}\right)$ may be considered to account for the out-of-plane shear lag effect of a channel brace bolted at the web only. While the term $\bar{x} / L$ is commonly referred to as a shear lag factor variable in the literature, following the terminology of Munse and Chesson (1963), it is more correctly considered to account for the detrimental bending moment effect resulting from the connection eccentricity $\bar{x}$ and for the counteracting bending moment effect that increases with the connection length $L$. The effects of $\bar{x}$ and $L$ on the longitudinal normal stresses in the web are illustrated in Fig. 2.

It should be noted that the term $\bar{x} / L$ was intended by Munse and Chesson (1963) to account for the out-of-plane shear lag effect, which is also present in a bisymmetric I-section connected at the flanges only, not for the bending moment effects, as is used in the present work.

\section{Test Materials}

The G450 sheet steel materials (trade name GALVASPAN) used in the laboratory tests were manufactured and supplied by Bluescope Steel Port Kembla Steelworks, Australia. Two nominal thicknesses were used, 1.5 and $3.0 \mathrm{~mm}$. Table 1 shows the average base metal

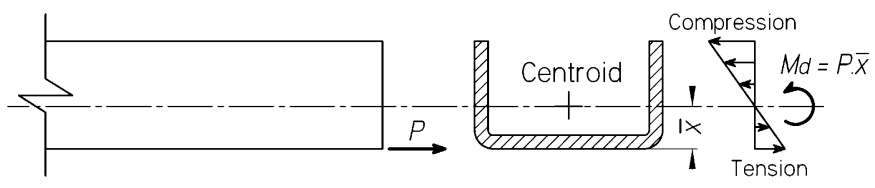

(a) Detrimental bending moment $M d$ due to connection eccentricity

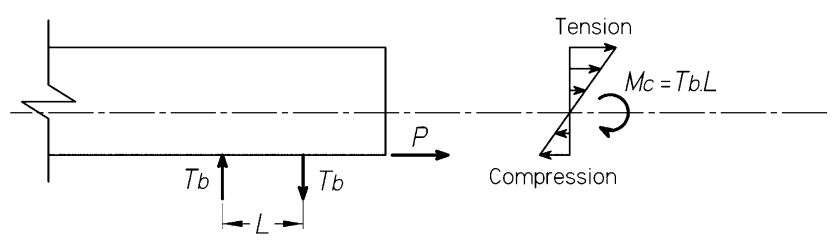

(b) Counter-acting moment $M c$ from bolt tension

Fig. 2. Moment effects: (a) detrimental bending moment resulting from connection eccentricity; (b) counteracting moment from bolt reaction

Table 1. Average Material Properties

\begin{tabular}{lcccccccc}
\hline $\begin{array}{l}\text { Nominal } \\
\text { thickness }\end{array}$ & $\begin{array}{c}t_{\text {base }} \\
(\mathrm{mm})\end{array}$ & $\begin{array}{c}F_{y} \\
(\mathrm{MPa})\end{array}$ & $\begin{array}{c}F_{u} \\
(\mathrm{MPa})\end{array}$ & $F_{u} / F_{y}$ & $\begin{array}{c}\varepsilon_{15} \\
(\%)\end{array}$ & $\begin{array}{c}\varepsilon_{25} \\
(\%)\end{array}$ & $\begin{array}{c}\varepsilon_{50} \\
(\%)\end{array}$ & $\begin{array}{c}\varepsilon_{u o} \\
(\%)\end{array}$ \\
\hline $1.5 \mathrm{~mm}$ & 1.48 & 605 & 630 & 1.04 & 21.3 & 18.0 & 12.0 & 6.8 \\
$3.0 \mathrm{~mm}$ & 2.95 & 530 & 580 & 1.09 & 29.3 & 22.0 & 15.3 & 8.1 \\
\hline
\end{tabular}

thicknesses, $t_{\text {base }}$; yield stresses, $F_{y}$; tensile strengths, $F_{u}$; elongations at fractures over 15-, 25-, and 50-mm gauge lengths, $\varepsilon_{15}, \varepsilon_{25}$, and $\varepsilon_{50}$, respectively; and uniform elongation outside the fracture, $\varepsilon_{u o}$, of the steel materials, as obtained from six 12.5mm-wide tension coupons. Tensile loadings of all coupons and bolted connection specimens are in the direction perpendicular to the rolling direction of the G450 sheet steel. The tension coupon tests were conducted at a constant stroke rate of $1 \mathrm{~mm} / \mathrm{min}$ resulting in a strain rate of $\sim 2 \times 10^{-4} / \mathrm{s}$ prior to necking.

The tensile strengths in the direction perpendicular to the rolling direction of 1.5- and 3.0-mm G450 sheet steels obtained in the present work, rounded to the nearest $5 \mathrm{MPa}$, are 6 and $10 \%$ higher than those obtained by Teh and Hancock (2005) in the rolling direction. Whereas Teh and Hancock (2005) did not provide the elongations at fracture, it is believed that the rolling direction is associated with higher ductility. In any case, the G450 sheet steels used in the present work represent the grades of steel covered by AS/ NZS 4600 (SA/SNZ 2005), which are among those having the lowest ductility and for which the nominal tensile strength and yield stress may be fully utilized in structural design calculations (Hancock 2007). Therefore, the use of the present materials represents a stringent verification of the design equations.

\section{Specimen Configurations and Test Arrangements}

The present test specimens were dimensioned to represent the ratios of flange width to web depth of channel braces encountered in the cold-formed steel construction industry. Such ratios typically range from 0.25 to 0.5 . The test specimens comprise channel sections having web depths of 80,100 , and $120 \mathrm{~mm}$, with flange widths ranging from 20 to $50 \mathrm{~mm}$.

Channel braces bolted at the web that have a single row of bolts only tend to fail in either block shear or bearing, as shown in Fig. 3. The 3-mm thick specimen failing in block shear shown in Fig. 3(a) had a web depth of $100 \mathrm{~mm}$ with a flange width of only $20 \mathrm{~mm}$ (an aspect ratio of 0.2 ), and a bolt-hole edge distance of $50 \mathrm{~mm}$. The 
block shear failure mode is characterized by the arching of the section between the two bolt holes (Teh and Clements 2012), and should not be confused with net section fracture. The 1.5-mm-thick specimen failing in bearing shown in Fig. 3(b) had the same web and flange dimensions as the $3.0-\mathrm{mm}$ specimens, but the edge distance of the bolt hole was $60 \mathrm{~mm}$, to prevent block shear failure. The bolthole diameter in both cases was $17 \mathrm{~mm}$, to accommodate 16- $\mathrm{mm}$ bolts. Channel sections with a single bolt tend to fail in either bearing or shear-out (Holcomb et al. 1995; Maiola et al. 2002). Therefore, net section fracture does not have a practical significance for channel braces with a single row of bolts or a single bolt.

All of the test specimens had two rows of bolts arranged in a rectangular pattern, as depicted in Fig. 1. The bolt spacings were at least three times the bolt diameter, as required by the codes (SA/SNZ 2005; AISI 2007). The specimens in which the connection length was approximately six times the bolt diameter (i.e., $100 \mathrm{~mm}$ for the specimens with $16-\mathrm{mm}$ bolts and $80 \mathrm{~mm}$ for those with $12-\mathrm{mm}$ bolts) can be considered to have three rows of bolts spaced at approximately three times the bolt diameter, as the counteracting bending moment effect illustrated in Fig. 2 should be the same.

As pointed out by Epstein and Aiuto (2002) and Pan (2004), the net section tension strength of a channel brace bolted at the web is affected by the flexural stiffness of the connecting element. The stiffer the connecting element, the greater the counteracting bending moment and therefore the greater the net section tension strength. In practice, channel braces are often bolted at the web to cleat plates as thin as $6 \mathrm{~mm}$. The present specimens were therefore connected to 6-mm plates that enabled them to bend, as shown in Fig. 4.

Each of the 3-mm-thick specimens had a total member length of $900 \mathrm{~mm}$, except for three that had a total member length of $500 \mathrm{~mm}$. It will be seen that this variable did not have a noticeable effect on the connection strength.

All of the 1.5-mm thick specimens had a total member length of $500 \mathrm{~mm}$.

Lipped channel braces were not tested in this study because such sections are normally used for members that are subject to compression, in which case the member compression capacity is the governing design criterion. For the purpose of determining the net section tension capacity of such a member, the section can be considered to be a plain channel by ignoring the lips without affecting the final design.

The bolted connection specimens were tested to failure using an Instron 8033 universal testing machine (see Fig. 5) at a stroke rate of $1 \mathrm{~mm} / \mathrm{min}$, which coincides with that used for the tension coupon tests. In the vicinity of the ultimate load associated with net section fracture, the elongation of either a bolted connection specimen or a tension coupon is concentrated in the yielded and/or necked region. Therefore, the stroke rate used in determining the ultimate test load, $P_{t}$, of a bolted connection specimen ideally should not be greater than that used in determining the material tensile strength, $F_{u}$, even though the overall length of the former is many times greater. A greater strain rate leads to a higher implied tensile strength (Kassar and $\mathrm{Yu}$ 1992).

\section{Experimental Test Results and Discussion}

In calculating the net section tension capacity, $P_{p}$, of a specimen, the measured values of the material properties and geometric dimensions, such as base metal thickness, web depth, flange width, bolthole diameter, and connection length were used. However, for legibility, only the nominal values are shown in the following tables.

Table 2 lists the relevant geometric dimensions and the test results of the $3.0-\mathrm{mm}$-thick specimens, which had a corner radius of $3 \mathrm{~mm}$.

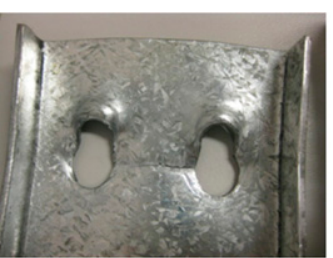

(a) Block shear failure

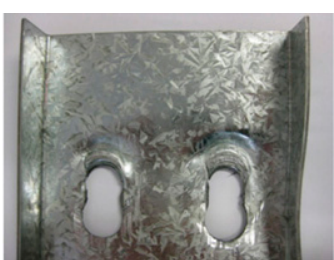

(b) Bearing
Fig. 3. Failure modes with only a single row of bolts: (a) block shear; (b) bearing

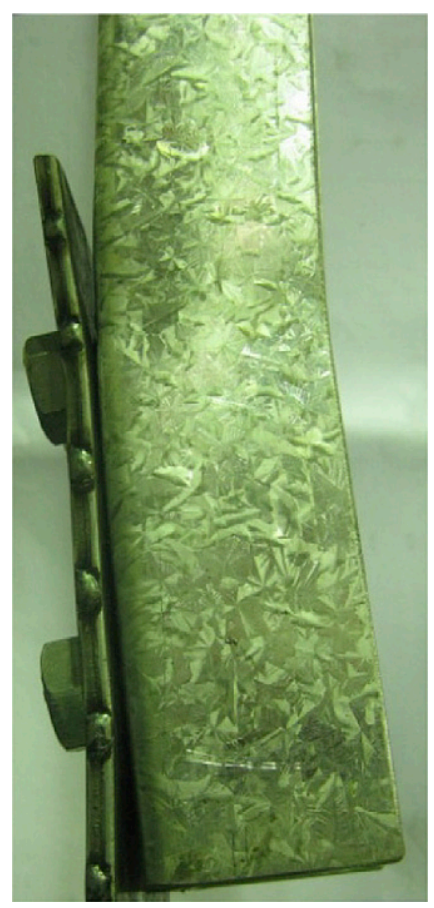

Fig. 4. Flexible connecting element

An empty cell in the table indicates that the data in the cell from the previous row applies. The variable $c$ denotes the actual net section efficiency factor, defined as the ratio of ultimate test load to net section tension capacity computed with the assumption of uniform stress distribution.

Table 2 shows the ratios of the ultimate test load, $P_{t}$, to the net section tension capacity, $P_{p}$, predicted by Eqs. (2)-(6) and (9). The first three are code equations, the next two have been proposed in the literature, and the last is the proposed equation. Eq. (6) is used in conjunction with the original definition of the connection eccentricity, $\bar{x}$, given by Pan (2004), which is the same as that used in all the other equations, shown in Fig. 1.

All of the specimens failed in the net section fracture mode, as illustrated in Fig. 6(a) for specimen $\mathrm{CH} 4$.

It can be seen from the results for specimens CH8-CH12_2 in Table 2 that the distance between the two connected ends of a member does not have any noticeable effect on the net section tension strength of the connection. Specimens CH8_2, CH10_2, and CH12_2 had a total member length of $500 \mathrm{~mm}$, whereas the other specimens had a total member length of $900 \mathrm{~mm}$. The absence of this variable in all of the equations described in this paper is therefore justified.

Table 2 shows that Eqs. (2)-(4) and (6) significantly overestimate the net section tension capacity of the present $3.0-\mathrm{mm}$ specimens. 


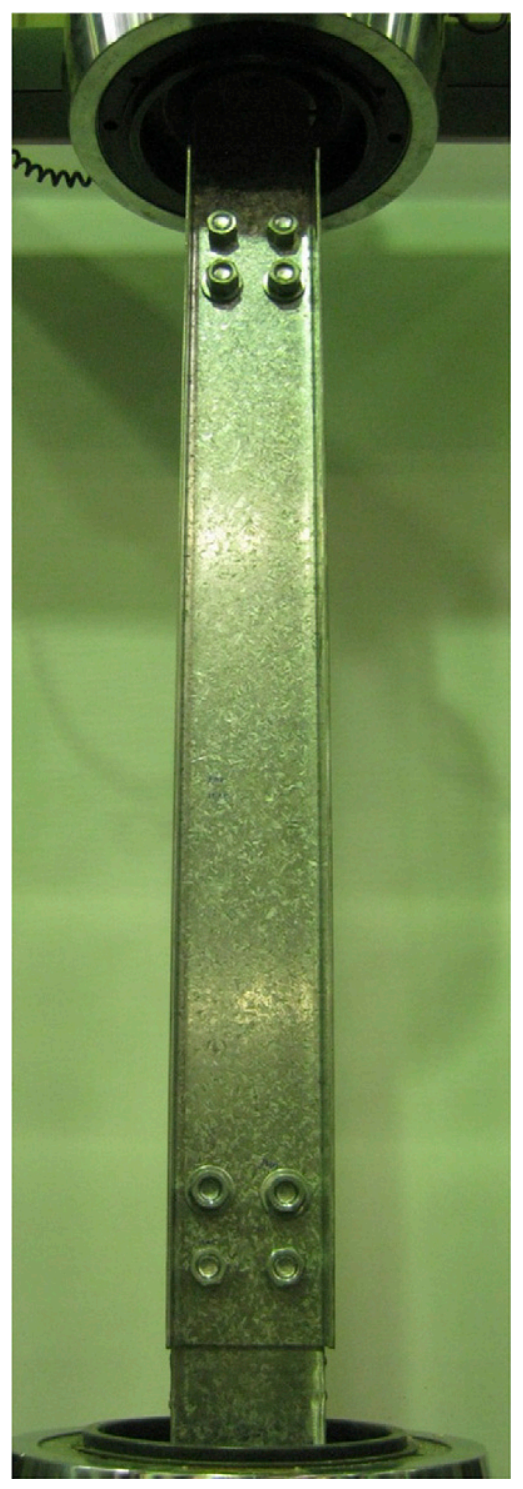

Fig. 5. Tension test setup

In contrast, Eqs. (5) and (9) predict the failure loads with reasonable accuracy.

It is interesting to note that whereas Eqs. (5) and (9) are very different in form from each other, their results for the 3.0-mm-thick specimens are fairly close to each other. Eq. (5) was derived by Holcomb et al. (1995), based on nonlinear regression analysis of laboratory test results for angle sections. The $P_{t} / P_{p}$ ratios given by Eq. (5) range from 0.94 to 1.19, whereas those given by Eq. (9) range from 0.96 to 1.13 .

Eq. (5) consistently overestimates the beneficial effect of increased connection lengths, as evident from the significant decrease in $P_{t} / P_{p}$ with increasing $L$ for a given channel size. The actual effect of increased connection length can be seen from the variation of the test net section efficiency factor $c$ with respect to the connection length $L$ for each channel size, as evident in Table 2.

Fig. 7 shows the variation of the test net section efficiency factor $c$ with respect to the flange width $W_{f}$ for the 3.0-mm specimens having 100-mm-deep webs, whereas Fig. 8 shows the variation of the same with respect to the web depth $W_{c}$ for the $3.0-\mathrm{mm}$ specimens having 40-mm-wide flanges. It can be seen from Figs. 7 and 8 that the net section efficiency of a channel brace decreases with increasing aspect ratios for a given web depth or flange width.
Table 3 lists the relevant geometric dimensions and the test results of the $1.5-\mathrm{mm}$ specimens, which had a corner radius of $2 \mathrm{~mm}$. An empty cell in the table indicates that the data in the cell from the previous row applies. The table shows the ratios of the ultimate test load, $P_{t}$, to the net section tension capacity, $P_{p}$, predicted by Eqs. (2)-(6) and (9).

All of the specimens failed in the net section fracture mode, as illustrated in Fig. 6(b) for specimen $\mathrm{CH} 7$.

As with the 3.0-mm-thick specimens, Eqs. (2)-(4) and (6) significantly overestimate the net section tension capacity of the 1.5-mm specimens.

For the 1.5-mm specimens, the proposed Eq. (9) is somewhat unconservative, in contrast to Eq. (5). This is because of the lower ductility of $1.5-\mathrm{mm}$ G450 sheet steel in the direction transverse to the rolling direction, as reflected in Table 1 . The lower ductility of the $1.5-\mathrm{mm}$ sheet steel is captured by the variable $t$ in Eq. (5). However, the coefficient of variation of Eq. (9) is much smaller than that of Eq. (5).

Eq. (3), specified in the North American cold-formed steel structures code (AISI 2010), gives a net section efficiency factor of 0.9 for all the tested specimens except for Specimen CH19. This equation led to even more optimistic estimates than Eq. (4), which is intended for hot-rolled steel connections, because of the coefficient 0.36 .

If Eq. (1) in the present paper specified in the Australasian code (SA/SNZ 2005) is used, thus assuming the explicit constant of 0.85 in Eq. (1) to be part of the efficiency factor, then the mean $P_{t} / P_{p}$ for the $3.0-\mathrm{mm}$ specimens will be 0.98 with a coefficient of variation of 0.097 and that for the $1.5-\mathrm{mm}$ specimens will be 0.91 with a coefficient of variation of 0.084 .

\section{Resistance Factor (or Capacity Reduction Factor)}

The overall average ratio of the ultimate test load $P_{t}$ to the net section tension capacity $P_{p}$ predicted by Eq. (9) for the 29 specimens is 1.00 , with a standard deviation of 0.052 . Therefore, it seems reasonable to treat these specimens as one population for the purpose of determining a uniform resistance factor to be applied to the proposed equation.

Section F1.1 of the North American specification (AISI 2007) specifies that the resistance factor $\phi$ of a design equation is determined as follows:

$$
\phi=C_{\phi}\left(M_{m} F_{m} P_{m}\right) e^{p}
$$

in which $C_{\phi}=$ calibration coefficient equal to 1.52 in the case of the Load and Resistance Factor Design (LRFD); $M_{m}=$ mean value of the material factor, equal to 1.187 in the present case; $F_{m}=$ mean value of the fabrication factor equal to 0.99 ; and $P_{m}=$ mean value of the professional factor equal to 1.00 , as stated in the previous paragraph. The statistical parameters of the material and fabrication factors of the (unwelded) 1.5- and 3.0-mm G450 sheet steels have been previously provided by Teh and Hancock (2005).

The power $p$ of the natural logarithmic base $e$ in Eq. (10) is

$$
p=-\beta_{0} \sqrt{V_{M}^{2}+V_{F}^{2}+C_{p} V_{P}^{2}+V_{Q}^{2}}
$$

in which $V_{M}=$ coefficient of variation of the material factor, equal to 0.03 in the present case; $V_{F}=$ coefficient of variation of the fabrication factor equal to $0.02 ; V_{P}=$ coefficient of variation of the professional factor equal to 0.065 , the minimum value specified in Section F1.1 of the specification; $C_{p}=$ correction factor equal to 1.11, as computed from the relevant equation given in Section F1.1; and $V_{Q}=$ coefficient of variation of load effects equal to 0.21 , as specified in Section F1.1. 
Table 2. Results of 3.0-mm-Thick Specimens

\begin{tabular}{|c|c|c|c|c|c|c|c|c|c|c|c|c|c|}
\hline \multirow[b]{2}{*}{ Specimen } & \multirow[b]{2}{*}{$d_{h}(\mathrm{~mm})$} & \multirow[b]{2}{*}{$W_{c}(\mathrm{~mm})$} & \multirow[b]{2}{*}{$W_{f}(\mathrm{~mm})$} & \multirow[b]{2}{*}{$\bar{x}(\mathrm{~mm})$} & \multirow[b]{2}{*}{$L(\mathrm{~mm})$} & \multirow[b]{2}{*}{$A_{n}\left(\mathrm{~mm}^{2}\right)$} & \multirow[b]{2}{*}{$c$} & \multicolumn{6}{|c|}{$P_{t} / P_{p}$} \\
\hline & & & & & & & & $(2)^{\mathrm{a}}$ & (3) & (4) & (5) & (6) & (9) \\
\hline $\mathrm{CH} 2$ & 17 & 100 & 30 & 6.90 & 50 & 381 & 0.73 & 0.86 & 0.81 & 0.85 & 1.08 & 0.77 & 1.04 \\
\hline $\mathrm{CH} 4$ & & & & & 75 & 386 & 0.78 & 0.91 & 0.86 & 0.85 & 1.02 & 0.78 & 1.07 \\
\hline CH6 & & & & & 100 & 389 & 0.79 & 0.93 & 0.88 & 0.85 & 0.95 & 0.78 & 1.07 \\
\hline $\mathrm{CH} 8$ & & & 40 & 10.2 & 50 & 449 & 0.64 & 0.76 & 0.71 & 0.81 & 1.07 & 0.75 & 0.98 \\
\hline CH8_2 & & & & & & 449 & 0.66 & 0.78 & 0.74 & 0.83 & 1.11 & 0.77 & 1.01 \\
\hline $\mathrm{CH} 10$ & & & & & 75 & 450 & 0.69 & 0.81 & 0.76 & 0.79 & 1.01 & 0.74 & 1.00 \\
\hline CH10_2 & & & & & & 449 & 0.66 & 0.77 & 0.73 & 0.76 & 0.97 & 0.71 & 0.96 \\
\hline $\mathrm{CH} 12$ & & & & & 100 & 450 & 0.70 & 0.83 & 0.78 & 0.78 & 0.95 & 0.74 & 1.00 \\
\hline CH12_2 & & & & & & 451 & 0.71 & 0.83 & 0.79 & 0.79 & 0.96 & 0.75 & 1.01 \\
\hline $\mathrm{CH} 14$ & & & 50 & 13.9 & 50 & 502 & 0.61 & 0.71 & 0.67 & 0.83 & 1.11 & 0.78 & 0.98 \\
\hline $\mathrm{CH} 16$ & & & & & 75 & 507 & 0.64 & 0.76 & 0.71 & 0.78 & 1.04 & 0.75 & 0.98 \\
\hline $\mathrm{CH} 18$ & & & & & 100 & 501 & 0.64 & 0.76 & 0.71 & 0.75 & 0.96 & 0.72 & 0.96 \\
\hline $\mathrm{CH} 19$ & 13 & 80 & 40 & 11.4 & 40 & 408 & 0.62 & 0.73 & 0.69 & 0.87 & 1.11 & 0.81 & 1.02 \\
\hline $\mathrm{CH} 20$ & & & & & 60 & 392 & 0.65 & 0.76 & 0.72 & 0.80 & 1.02 & 0.76 & 0.99 \\
\hline $\mathrm{CH} 21$ & & & & & 80 & 407 & 0.66 & 0.77 & 0.73 & 0.77 & 0.95 & 0.74 & 0.98 \\
\hline $\mathrm{CH} 22$ & & & 20 & 4.60 & 40 & 290 & 0.76 & 0.89 & 0.84 & 0.86 & 1.02 & 0.78 & 1.05 \\
\hline $\mathrm{CH} 23$ & & & & & 60 & 287 & 0.82 & 0.96 & 0.91 & 0.89 & 0.97 & 0.81 & 1.10 \\
\hline $\mathrm{CH} 24$ & & & & & 80 & 294 & 0.86 & 1.01 & 0.95 & 0.91 & 0.94 & 0.83 & 1.13 \\
\hline $\mathrm{CH} 25$ & 17 & 120 & 40 & 9.30 & 50 & 506 & 0.71 & 0.84 & 0.79 & 0.87 & 1.19 & 0.80 & 1.06 \\
\hline $\mathrm{CH} 26$ & & & & & 75 & 500 & 0.73 & 0.86 & 0.81 & 0.83 & 1.07 & 0.77 & 1.04 \\
\hline $\mathrm{CH} 27$ & & & & & 100 & 502 & 0.75 & 0.88 & 0.83 & 0.82 & 1.01 & 0.77 & 1.04 \\
\hline Mean & & & & & & & & 0.83 & 0.78 & 0.82 & 1.03 & 0.77 & 1.02 \\
\hline Coefficient of variation & & & & & & & & 0.097 & 0.096 & 0.054 & 0.066 & 0.039 & 0.045 \\
\hline
\end{tabular}

${ }^{\mathrm{a}}$ Numbers in parentheses $=$ equation numbers.

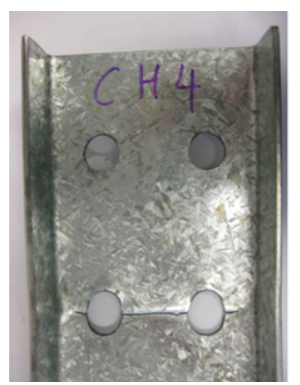

(a) $3.0 \mathrm{~mm}$ thick specimen

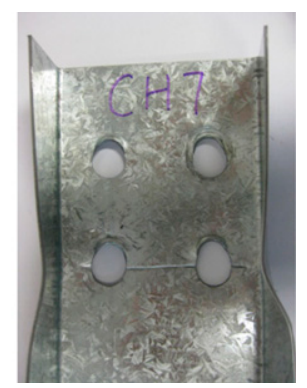

(b) $1.5 \mathrm{~mm}$ thick specimen
Fig. 6. Net section fracture: (a) 3.0-mm specimen; (b) $1.5-\mathrm{mm}$ specimen

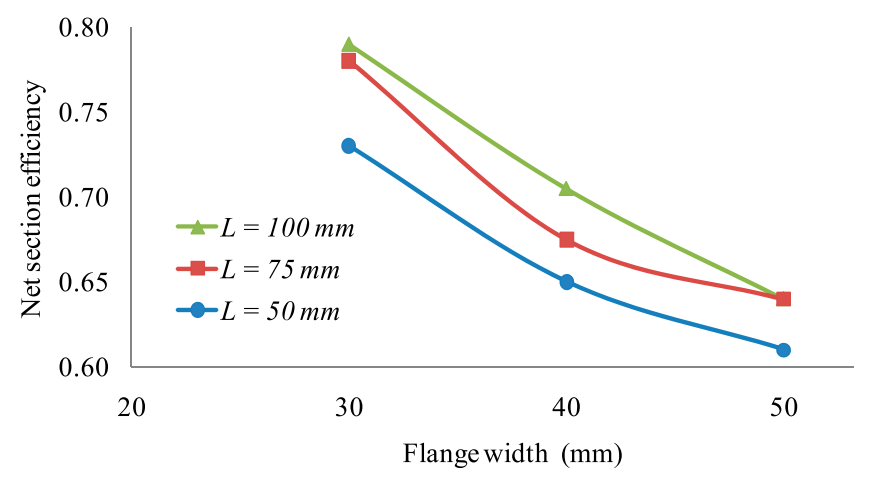

Fig. 7. Variation of net section efficiency factors with flange width $\left(W_{c}=100 \mathrm{~mm}\right)$

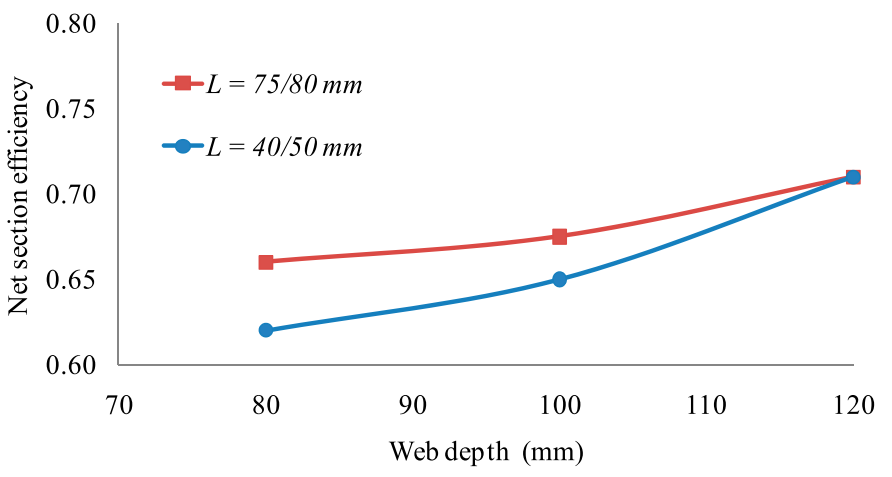

Fig. 8. Variation of net section efficiency factors with web depth $\left(W_{f}=40 \mathrm{~mm}\right)$

It was found that to achieve the target reliability index $\beta_{0}$ of 3.5 in the LRFD, Eq. (10) yields a resistance factor of 0.82 .

Therefore, a resistance factor $\phi$ equal to 0.80 (rounded down to the nearest 0.05) in conjunction with Eq. (9) is recommended for the LRFD approach for determining the net section tension capacity of a cold-formed steel channel brace bolted only at the web. This value is higher than the current value of 0.65 , specified in the North American cold-formed steel code (AISI 2007), and the effective capacity reduction factor of 0.765 , being 0.85 times 0.90 , specified in the Australasian code (SA/SNZ2005), reflects the greater reliability of the proposed Eq. (9) compared with Eqs. (2) and (3).

The implications of using the nominal tensile strength of 480 $\mathrm{MPa}$ in conjunction with the corresponding resistance factors to determine the design capacity, $P_{d}$, of the present specimens are shown in Table 4. The resistance factors specified in the North American and the Australasian cold-formed steel structures codes led to safe designs of the tested specimens. Interestingly, the designs 
Table 3. Results of 1.5-mm-Thick Specimens

\begin{tabular}{|c|c|c|c|c|c|c|c|c|c|c|c|c|c|}
\hline \multirow[b]{2}{*}{ Specimen } & \multirow[b]{2}{*}{$d_{h}(\mathrm{~mm})$} & \multirow[b]{2}{*}{$W_{c}(\mathrm{~mm})$} & \multirow[b]{2}{*}{$W_{f}(\mathrm{~mm})$} & \multirow[b]{2}{*}{$\bar{x}(\mathrm{~mm})$} & \multirow[b]{2}{*}{$L(\mathrm{~mm})$} & \multirow[b]{2}{*}{$A_{n}\left(\mathrm{~mm}^{2}\right)$} & \multirow[b]{2}{*}{$c$} & \multicolumn{6}{|c|}{$P_{t} / P_{p}$} \\
\hline & & & & & & & & (2) & (3) & (4) & (5) & (6) & (9) \\
\hline $\mathrm{CH} 1$ & 17 & 100 & 30 & 6.28 & 50 & 190 & 0.67 & 0.79 & 0.75 & 0.77 & 1.05 & 0.70 & 0.95 \\
\hline $\mathrm{CH} 3$ & & & & & 75 & 185 & 0.72 & 0.85 & 0.80 & 0.79 & 1.01 & 0.73 & 0.99 \\
\hline CH5 & & & & & 100 & 188 & 0.74 & 0.88 & 0.83 & 0.79 & 0.95 & 0.74 & 1.00 \\
\hline $\mathrm{CH} 7$ & & & 40 & 9.56 & 50 & 220 & 0.61 & 0.72 & 0.68 & 0.76 & 1.09 & 0.70 & 0.93 \\
\hline $\mathrm{CH} 11$ & & & & & 100 & 217 & 0.67 & 0.79 & 0.75 & 0.75 & 0.98 & 0.70 & 0.95 \\
\hline $\mathrm{CH} 13$ & & & 50 & 13.2 & 50 & 248 & 0.59 & 0.69 & 0.65 & 0.79 & 1.16 & 0.75 & 0.95 \\
\hline $\mathrm{CH} 15$ & & & & & 75 & 248 & 0.62 & 0.72 & 0.68 & 0.75 & 1.08 & 0.72 & 0.94 \\
\hline $\mathrm{CH} 17$ & & & & & 100 & 246 & 0.63 & 0.74 & 0.70 & 0.73 & 1.02 & 0.71 & 0.94 \\
\hline Mean & & & & & & & & 0.77 & 0.73 & 0.77 & 1.04 & 0.72 & 0.96 \\
\hline Coefficient of variation & & & & & & & & 0.084 & 0.084 & 0.033 & 0.064 & 0.024 & 0.028 \\
\hline
\end{tabular}

Table 4. Implications of Resistance Factors and Nominal Tensile Strengths

\begin{tabular}{lccc}
\hline & \multicolumn{3}{c}{$P_{t} / P_{p}$} \\
\cline { 2 - 4 } Nominal thickness & $(1)^{\mathrm{a}} \phi=0.90$ & (3) $\phi=0.65$ & (9) $\phi=0.80$ \\
\hline $1.5 \mathrm{~mm}$ & 1.33 & 1.48 & 1.57 \\
$3.0 \mathrm{~mm}$ & 1.31 & 1.46 & 1.54 \\
\hline
\end{tabular}

${ }^{\mathrm{a}}$ Numbers in parentheses $=$ equation numbers.

for the less ductile $1.5-\mathrm{mm}$ specimens were more conservative as a result of their higher actual tensile strengths of $630 \mathrm{MPa}$ compared with those for the 3.0-mm specimens, which had actual tensile strengths of $580 \mathrm{MPa}$.

\section{Conclusions}

It has been shown that there are three distinct factors affecting the net section efficiency of a cold-formed steel channel brace bolted at the web only. These factors are (1) the in-plane shear lag associated with stress concentration around a bolt hole that is also present in flat sheets, (2) the out-of-plane shear lag phenomenon that is also present in a bisymmetric I-section bolted at the flanges only, and (3) the bending moment arising from the connection eccentricity with respect to the neutral axis.

For the first time, each of the relevant factors is explicitly incorporated into the equation proposed in this paper for determining the net section tension capacity of a cold-formed steel channel brace bolted at the web only.

It has been shown through laboratory tests on low ductility channel braces having practical aspect ratios that were bolted at the web to flexible plates that the proposed equation is more reliable than the equations prescribed in the AISC, AISI, and AS/NZS steel structures codes. The equation proposed in this paper is also more robust and more transparent than those existing in the literature, which were derived through regression analysis of laboratory test results for angle sections and channel sections with relatively rigid connecting elements.

It is proposed that a resistance factor of 0.80 be applied to the new equation to ensure a reliability index of not less than 3.5 in the LRFD approach of the North American specification for the design of cold-formed steel structures.

\section{Acknowledgments}

The authors thank John Kralic, Manager, Lysaght Research and Technology, Bluescope Steel Limited, for supplying the G450 sheet steel materials used in this work. The authors thank Gregory Hancock, Emeritus Professor, University of Sydney, for his expert input concerning the state-of-the-art of bolted connection design in cold-formed sheet steel. The authors also thank Chris Cook, Dean of Engineering, and Muhammad Hadi, Head of the Advanced Structural Engineering and Construction Materials Group, both from the University of Wollongong, for supporting the laboratory tests that were conducted in the High Bay Laboratory of the Faculty of Engineering. The specimens were fabricated by Ritchie McLean and tested with the assistance of Jack Atkinson, an honors thesis student at the University of Wollongong.

\section{Notation}

The following symbols are used in this paper:

$A_{n}=$ net area of considered section;

$C_{p}=$ correction factor;

$C_{\phi}=$ calibration coefficient;

$c=$ test net section efficiency;

$d=$ bolt diameter;

$F_{m}=$ mean value of fabrication factor;

$F_{u}=$ tensile strength of steel material;

$F_{y}=$ yield stress of steel material;

$k_{t}=$ net section efficiency factor according to AS/ NZS 4600:2005;

$L=$ connection length;

$M_{m}=$ mean value of material factor;

$P_{m}=$ mean value of professional factor;

$P_{p}=$ predicted failure load;

$t=$ nominal sheet thickness;

$t_{\text {base }}=$ base metal thickness;

$V_{F}=$ coefficient of variation of fabrication factor;

$V_{M}=$ coefficient of variation of material factor;

$V_{P}=$ coefficient of variation of professional factor;

$V_{Q}=$ coefficient of variation of load effects;

$W_{c}=$ web depth;

$W_{f}=$ flange width;

$\bar{x}=$ connection eccentricity;

$\beta_{0}=$ target reliability index;

$\varepsilon_{15}=$ elongation at fracture over gauge length of 15 $\mathrm{mm}$;

$\varepsilon_{25}=$ elongation at fracture over gauge length of 25 $\mathrm{mm}$;

$\varepsilon_{50}=$ elongation at fracture over gauge length of 50 $\mathrm{mm}$; 

$\varepsilon_{\mathrm{uo}}=$ uniform elongation outside fracture zone; and
$\phi=$ resistance factor (or capacity reduction factor).

\section{References}

AISC. (1993). Load and resistance factor design specification for structural steel buildings, Chicago.

AISC. (1999). Load and resistance factor design specification for structural steel buildings, Chicago.

AISC. (2010). "Specification for structural steel buildings." ANSI/AISC 36010, Chicago.

American Iron and Steel Institute (AISI). (2007). North American specification for the design of cold-formed steel structural members, Washington, DC.

American Iron and Steel Institute (AISI). (2010). Supplement No. 2 to the North American specification for the design of cold-formed steel structural members, 2007 edition, Washington, DC.

Chesson, E. (1959). Behaviour of large riveted and bolted structural connections." Ph.D. thesis, Univ. of Illinois, Urbana-Champaign, IL.

Epstein, H. I., and Aiuto, C. L. D. (2002). "Using moment and axial interaction equations to account for moment and shear lag effects in tension members." AISC Eng. J., 39(2), 91-99.

Hancock, G. J. (2007). Design of cold-formed steel structures, 4th Ed., Australian Steel Institute, Sydney, Australia.

Holcomb, R. D., LaBoube, R. A., and Yu, W. W. (1995). "Tensile and bearing capacities of bolted connections." Second Summary Rep., Civil Engineering Study 95-1, Cold-Formed Steel Series, Dept. of Civil Engineering, Center for Cold-Formed Steel Structures, Univ. of Missouri-Rolla, Rolla, MO.
Kassar, M., and Yu, W. W. (1992). "Effect of strain rate on material properties of sheet steels." J. Struct. Eng., 118(11), 3136-3150.

Kirkham, W. J., and Miller, T. H. (2000). "Examination of AISC LRFD shear lag design provisions.” AISC Eng. J., 37(3), 83-98.

LaBoube, R. A., and Yu, W. W. (1996). "Additional design considerations for bolted connections." Proc., 13th Int. Specialty Conf. Cold-Formed Steel Structures, American Iron and Steel Institute, Washington, DC, $575-593$

Maiola, C. H., Malite, M., Goncalves, R. M., and Neto, J. M. (2002). "Structural behaviour of bolted connections in cold-formed steel members, emphasizing the shear lag effect." Proc., 16th Int. Specialty Conf. Cold-Formed Steel Structures, American Iron and Steel Institute, Washington, DC, 697-708.

Munse, W. H., and Chesson, E. (1963). "Riveted and bolted joints: Net section design." J. Struct. Div., 89(1), 107-126.

Pan, C.-L. (2004). "Prediction of the strength of bolted cold-formed channel sections in tension." Thin-Walled Struct., 42(8), 1177-1198.

Standards Australia (SA). (1998). "Steel structures." AS 4100-1998, Sydney, Australia.

Standards Australia (SA). (1999). "Steel structures-Commentary." Supplement to AS 4100-1998, Sydney, Australia.

Standards Australia/Standards New Zealand (SA/SNZ). (2005). "Coldformed steel structures." AS/NZS 4600:2005, Sydney, Australia.

Teh, L. H., and Clements, D. D. A. (2012). "Block shear capacity of bolted connections in cold-reduced steel sheets." J. Struct. Eng., 138(4), 459467.

Teh, L. H., and Gilbert, B. P. (2012). "Net section tension capacity of bolted connections in cold-reduced steel sheets." J. Struct. Eng, 138(3), $337-344$.

Teh, L. H., and Hancock, G. J. (2005). "Strength of welded connections in G450 sheet steels.” J. Struct. Eng., 131(10), 1561-1569. 